\title{
Uso de blogs en Ciencias de la Actividad Física y el Deporte*
}

\author{
Luis Antolín \\ Profesor Titular de Escuela Universitaria del Departament d’Educació Física i Esportiva de la Universitat de València \\ luis.antolin@uv.es
}

\section{J. Pere Molina}

Profesor Titular de Escuela Universitaria del Departament d'Educació Física i Esportiva de la Universitat de València juan.p.molina@uv.es

\section{Miguel Villamón}

Profesor Titular de Universidad del Departament d'Educació Física i Esportiva de la Universitat de València miguel.villamon@uv.es

\section{José Devís-Devís}

Catedrático de Universidad del Departament d'Educació Física i Esportiva de la Universitat de València jose.devis@uv.es

\section{Víctor Pérez-Samaniego}

Profesor Titular de Universidad del Departament d’Educació Física i Esportiva de la Universitat de València victor.m.perez@uv.es

|Fecha presentación: 16/09/2010 | Aceptación: 07/07/2011 |Publicación: 23/12/2011

\section{Resumen}

Se describe la experiencia de un proyecto de innovación educativa que consistió en el diseño, desarrollo y evaluación de diversos usos de blogs y que se desarrolló en la Facultat de Ciències de l'Activitat Física i l'Esport de la Universitat de València, durante el curso académico 2009-10. El análisis refleja la heterogeneidad con la que los diferentes profesores dieron respuesta a los problemas específicos planteados en sus materias. La principal conclusión es que esta flexibilidad en el uso de los blogs supone una singular ventaja para la innovación en educación superior centrada en el aprendizaje de los estudiantes.

Palabras clave: blogs, innovación educativa, educación superior, educación física

\section{Resum}

Es descriu l'experiència d'un projecte d'innovació educativa que va consistir en el disseny, desenvolupament i avaluació de diversos usos de blocs i que es va desenvolupar a la Facultat de Ciències de l'Activitat Física i l'Esport de la Universitat de València, durant el curs acadèmic 2009-10. L'anàlisi reflexa l'heterogeneïtat en què els diferents professors donen resposta als problemes específics plantejats en les seues matèries. La principal conclusió és que aquesta flexibilitat en l'ús dels blocs suposa un singular avantatge per a la innovació en l'educació superior centrada en l'aprenentatge dels estudiants.

Paraules clau: blocs, innovació educativa, educació superior, educació física

\section{Abstract}

This paper describes an experiencie of an innovative educational project developed in the University of Valencia at the Faculty of Physical Activity and Sport Sciences during the academic year 2009-10 which included the design, implementation and evaluation of several blogs. Heterogeneous use according to specific needs of different subjects is shown. Flexibility in the use of blogs is considered the main advantage of its use according to a learning-centred approach in higher education.

Keywords: blogs, education innovation, higher education, physical education * Trabajo derivado del Proyecto de innovación educativa 2010 de la Universitat de València “Diseño, desarrollo y evaluación de diversos usos de weblogs
como recursos de innovación educativa”. Los autores agradecen a Eloy López Meneses sus críticas y sugerencias para la mejora de este artículo. 


\section{Introducción}

La universidad española está inmersa en un proceso de convergencia hacia el Espacio Europeo de Educación Superior (EEES). Uno de los elementos clave que encontramos es la nueva organización docente a partir del concepto de crédito ECTS (European Credit Transfer System). Mientras en el sistema tradicional el crédito representaba el número de horas de clase que un profesor impartía, en el sistema europeo los créditos ECTS representan el volumen de trabajo del estudiante para conseguir los objetivos del programa de estudios. Planificar con créditos ECTS consiste, por tanto, en especificar la carga de trabajo que le supone al estudiante realizar el conjunto de actividades que integran la propuesta didáctica de una materia. Pero la adopción del sistema de transferencia de créditos europeos no se reduce a un cambio en la dedicación horaria. Implica una reorganización del sistema de enseñanza para adaptarlo a un modelo de formación centrado en el trabajo y aprendizaje de los estudiantes. El cambio consiste en pasar de metodologías centradas en la enseñanza a las centradas en el aprendizaje (MECD, 2003; Servei de Formació Permanent, 2005; CRMEU, 2006). Una de las principales innovaciones que debe llevarse a cabo se encuentra, pues, en el protagonismo que deben adquirir los estudiantes y en el desarrollo de competencias y metodologías que propicien su aprendizaje autónomo y reflexivo.

En los créditos ECTS se considera tanto el trabajo presencial como el no presencial del alumnado, lo que hace necesario un replanteamiento hacia nuevas estrategias docentes, como pueden ser las generadas a través del uso de herramientas de la web 2.o. Una de las herramientas con más posibilidades de uso docente son los blogs cuyas características, diferentes de las páginas web tradicionales, los hacen especialmente adecuados a las nuevas exigencias del proceso de enseñanza-aprendizaje: fácil manejo y participación, contenidos multimedia e interacción social. Los blogs educativos o edublogs pueden ser un recurso importante dentro del método de aprendizaje activo, autónomo y reflexivo propuesto en el marco del EEES. Se trata de un tema que ha suscitado un enorme interés tanto en el contexto español (Aguaded, López Meneses y Alonso Díaz, 2010; Blanco, 2005; Gewerc, 2005; González Sánchez y García Muiña, 2009; López Meneses y Martín Sánchez, 2009; Marzal y Butera, 2007; Orihuela y Santos, 2004) como internacional (Farmer, Yue y Brooks, 2008; Ladyshewsky y Gardner, 2008; Philip y Nicholls, 2009; Williams y Jacobs, 2004).

Ante el inicio de la implantación progresiva de los estudios de Grado en la Facultat de Ciències de l'Activitat Física i l'Esport (FCAFE) de la Universitat de València, en el curso 200910, el grupo de profesores que conformamos la Unidad de Investigación de Teoría y Pedagogía de la Actividad Física y el Deporte (UTPAFIDE), decidimos constituirnos como Grupo de Innovación Educativa (GID) y presentar un proyecto, relacionado con el diseño, desarrollo y evaluación de diversos usos de blogs, a una convocatoria específica de innovación educativa de nuestra universidad. La experiencia que vamos a describir en este artículo es fruto de dicho proyecto.

\section{Objetivos del proyecto}

El proyecto de diseño, desarrollo y evaluación de diversos usos de blogs como recursos de innovación educativa pretende potenciar el trabajo interdisciplinar y en equipo del profesorado de la FCAFE, así como promover el desarrollo de competencias de los estudiantes relacionadas con el tra- tamiento de la información y el uso de las TIC (Tecnologías de la Información y Comunicación). Para conseguir esta finalidad se identifican los siguientes objetivos:

- Establecer el equipo de profesorado como GID y formarlos en la utilización de los blogs como herramienta didáctica.

- Caracterizar diversos tipos, metodologías y usos innovadores de los blogs en la docencia universitaria en función de su contribución al desarrollo de competencias relacionadas con el análisis y el tratamiento de la información y con la utilización de las TIC por parte del alumnado.

- Establecer la contribución del uso de los blogs en la adaptación de las asignaturas participantes en el proyecto al EEES, integrando su uso en la Guía Docente de las asignaturas implicadas en la experiencia y poniéndolos en práctica.

- Valorar la experiencia y establecer conclusiones del proyecto llevado a término, difundiendo los resultados a través de congresos y publicaciones.

\section{Profesorado y asignaturas del proyecto}

Todas las asignaturas integradas en la experiencia pertenecen a la Licenciatura en Ciencias de la Actividad Física y el Deporte, aunque sus Guías Docentes han sido adaptadas a las nuevas exigencias de diseño de la convergencia europea. En cuanto al profesorado participante, éste pertenece al De-

\begin{tabular}{|c|c|c|}
\hline Asignatura & $\begin{array}{l}\text { Características } \\
\text { académicas de la } \\
\text { asignatura }\end{array}$ & $\begin{array}{l}\text { Profesorado } \\
\text { y grupos de } \\
\text { estudiantes } \\
\text { participantes }\end{array}$ \\
\hline Judo & $\begin{array}{l}\text { Troncal anual de 1er } \\
\text { ciclo (3er curso) de } 9 \\
\text { créditos prácticos. }\end{array}$ & $\begin{array}{l}\text { Un profesor con } 3 \\
\text { grupos de práctica } \\
\text { con un total de } 90 \\
\text { estudiantes }\end{array}$ \\
\hline $\begin{array}{l}\text { Danza y } \\
\text { Dramatización }\end{array}$ & $\begin{array}{l}\text { Optativa cuatrimes- } \\
\left.\text { tral ( } 2^{\mathrm{O}} \text { semestre }\right) \text { de } \\
\text { er ciclo. } 6 \text { créditos } \\
\text { prácticos. }\end{array}$ & $\begin{array}{l}\text { Un profesor con } 1 \\
\text { grupo de práctica de } \\
30 \text { estudiantes }\end{array}$ \\
\hline $\begin{array}{l}\text { Expresion } \\
\text { Corporal }\end{array}$ & $\begin{array}{l}\text { Troncal anual de } 1 \text { er } \\
\text { ciclo }\left(2^{\circ} \text { curso) de } 6\right. \\
\text { créditos prácticos. }\end{array}$ & $\begin{array}{l}\text { Un profesor con } 4 \\
\text { grupos de práctica } \\
\text { con un total de } 120 \\
\text { estudiantes. }\end{array}$ \\
\hline $\begin{array}{l}\text { Deporte y } \\
\text { Recreación }\end{array}$ & $\begin{array}{l}\text { Troncal cuatrimestral } \\
\left(2^{\circ} \text { semestre) de } 2^{\circ}\right. \\
\text { ciclo ( } 5^{\circ} \text { curso) de } 4 \text { '5 } \\
\text { créditos ( } 3 \text { teóricos y } \\
1^{\prime} 5 \text { prácticos). }\end{array}$ & $\begin{array}{l}\text { Un profesor con } 1 \\
\text { grupo de teoría y } 4 \\
\text { de práctica con un } \\
\text { total de } 133 \\
\text { estudiantes. }\end{array}$ \\
\hline $\begin{array}{l}\text { Diseño } \\
\text { curricular de la } \\
\text { Educación } \\
\text { Física }\end{array}$ & $\begin{array}{l}\text { Troncal cuatrimestral } \\
\text { (1er semestre) de } 2^{\circ} \\
\text { ciclo ( } 5^{\circ} \text { curso) de } 4 \text { '5 } \\
\text { créditos ( } 3 \text { teóricos y } \\
1^{\prime} 5 \text { prácticos). }\end{array}$ & $\begin{array}{l}\text { Un profesor con } 1 \\
\text { grupo de teoría y } 4 \\
\text { de práctica con un } \\
\text { total de } 148 \\
\text { estudiantes. }\end{array}$ \\
\hline $\begin{array}{l}\text { Proyectos y } \\
\text { materiales } \\
\text { curriculares en } \\
\text { Educación } \\
\text { Física }\end{array}$ & $\begin{array}{l}\text { Optativa cuatrimes- } \\
\text { tral (1er semestre) de } \\
\text { 1er ciclo de 4'5 } \\
\text { créditos ( } 3 \text { teóricos y } \\
\text { 1'5 prácticos). }\end{array}$ & $\begin{array}{l}\text { Un profesor con } \\
1 \text { grupo } \\
\text { teórico-práctico de } \\
33 \text { estudiantes. }\end{array}$ \\
\hline $\begin{array}{l}\text { Teoría y } \\
\text { práctica del } \\
\text { curriculum de } \\
\text { la Educación } \\
\text { Física }\end{array}$ & $\begin{array}{l}\text { Troncal anual de } 2^{0} \\
\text { ciclo ( } 4^{\mathrm{O}} \text { curso) de } 9 \\
\text { créditos ( } 6 \text { teóricos y } \\
3 \text { prácticos). }\end{array}$ & $\begin{array}{l}\text { Dos profesores con } 2 \\
\text { grupos de teoría y } 6 \\
\text { de práctica con un } \\
\text { total de } 176 \\
\text { estudiantes. }\end{array}$ \\
\hline
\end{tabular}

Tabla 1.- Asignaturas, características académicas, profesorado y grupos de estudiantes participantes 
partamento de Educación Física y Deportiva, más concretamente a su Unidad. En la tabla 1 pueden verse las asignaturas que integran este proyecto, sus características académicas y el profesorado y grupos de estudiantes participantes en el proyecto.

\section{Desarrollo del proyecto de innovación}

Para el seguimiento de la experiencia se recurrió al seminario colaborativo (Fraile, 2002), entendido como una técnica activa de enseñanza e investigación, basada en el trabajo en grupo e intercambio de información, utilizada para profundizar desde el debate y análisis colectivo en un tema determinado, en nuestro caso el uso de blogs en diversas asignaturas de la FCAFE.

Una de las primeras tareas que abordamos fue la decisión de la plataforma desde la cual se crearian los blogs. Aunque la Universitat de València utiliza la plataforma Worpress, nuestro grupo decidió utilizar Blogger por varias razones:

- Gratuidad y libertad en su uso.

- Conocimiento de experiencias docentes universitarias que avalan el uso de esta plataforma (p.e. Gewerc, 2005; López Meneses y Martín Sánchez, 2009; Orihuela y Santos, 2004).

- Existencia de dos miembros del GID con experiencia previa en el uso de la misma.

- Facilidad en la creación del blog y manejo muy intuitivo.

- Facilidad en la carga de imágenes e inserción de archivos multimedia dada su total compatibilidad con otros servicios on-line de almacenamiento de archivos multimedia. - Disponibilidad de multitud de herramientas y utilidades compatibles.

La experiencia se desarrolló durante el curso académico 2009-10 a través de tres fases que se describen a continuación:

$1^{a}$ Fase: Formación en la creación, configuración y funcionamiento de los blogs de los miembros de GID

Esta fase se desarrolló a través de tres jornadas de carácter interno, durante la primera mitad mes de septiembre de 2009, en las que uno de los miembros del GID, con experiencia previa en el uso didáctico de blogs, explicó al resto de componentes los aspectos relacionados con la creación y funcionamiento básico de los blogs. En esta fase también se analizaron algunos edublogs y se comenzaron a plantear posibilidades de uso para los blogs de nuestras asignaturas. Al finalizar esta fase los miembros del GID, sin experiencia previa en el uso de blogs, tenían dados de alta sus perfiles en Google (condición necesaria para abrir un blog en Blogger) y tenían sus blogs con una configuración elemental y disponían de un conocimiento técnico básico para generar entradas con hipervículos, imágenes o vídeos, así como algunas nociones elementales para realizar cambios en la configuración de sus blogs.

$2^{a}$ Fase: Diseño de la experiencia

Durante esta fase, que se desarrolló en la segunda quincena de septiembre, se definieron los problemas y necesidades docentes a los que se podía dar respuesta con el uso del blog en las asignaturas.

Como resultado de la discusión relativa a las necesidades se puso de manifiesto que no se trataba añadir algo nuevo al programa de las asignaturas ni tampoco buscar un uso igual o similar para todas ellas. Más bien se vio la necesidad de utilizar el blog para que facilitara la tarea real del profesor y el desarrollo de su programa. Así es como aparecen usos diversos adaptados a necesidades particulares de cada profesor y asignatura que se concretan en la fase siguiente.

En relación con estos problemas y necesidades se plantearon inicialmente diversas posibilidades generales de uso que se recogieron en las Guías Docentes de las asignaturas y que se terminaron de concretar en la fase que se comenta a continuación.

$3^{a}$ Fase: Puesta en práctica y análisis de la experiencia

Esta fase tuvo lugar durante el periodo lectivo del curso 2009-10, pero hay que diferenciar que, dependiendo de la duración de la asignatura (anual o cuatrimestral), se desarrollaron a lo largo de todo el curso (caso de las asignaturas de Judo y Teoría y Práctica del Currículum de la EF), sólo durante el primer cuatrimestre (Expresión Corporal, Diseño Curricular de la EF y Proyectos y Materiales Curriculares en $E F$ ) o sólo durante el segundo (Deporte y Recreación y Danza y Dramatización).

También cabe advertir que estamos ante un proyecto de innovación educativa que lo que busca no es la recopilación de datos para su posterior análisis, sino que este análisis vaya parejo a la recopilación de datos de la experiencia. No se quiere mejorar el proceso de enseñanza-aprendizaje al final de la experiencia, sino durante la misma. Por este motivo, esta fase aunó los procesos de desarrollo y análisis de la experiencia. De una parte, los diversos profesores del GID pusieron en práctica sus blogs integrándolos en la docencia de sus asignaturas y tomando datos sobre este proceso. Y, de otra, se realizó un seguimiento y análisis de la puesta en práctica de los blogs a través del seminario colaborativo permanente.

A partir de los problemas y necesidades definidas en la segunda fase, durante esta tercera fase se materializaron los diversos usos de blogs que se resumen en la tabla 2.

Judo

http://judo2009.blogspot.com

Videoblog dedicado a la presentación de ejemplos de ejecución de las distintas técnicas y contenidos prácticos. Los post contienen videos de ejecución de técnicas y ejemplos sobre métodos de práctica del Judo.

La selección o incluso la creación de materiales audiovisuales que muestren la ejecución de estas técnicas y su muestra por medio del blog, permitió que las técnicas que se estudiaban en clase pudieran ser analizadas y practicadas fuera del horario docente. Además, la disposición de esta información de forma permanente permitió a los alumnos trabajar y comprender estas técnicas en el horario que, de forma autónoma, dedican a la asignatura.

Tabla 2. Asignaturas, dirección URL del blog ${ }^{1} y$ descripción del uso didáctico

\footnotetext{
${ }^{1}$ Es posible que alguno de estos blogs no tenga abierto su acceso a partir del curso 2010-11, pues cada blog es específico de un curso y su uso se inicia y se finaliza con el curso académico. En caso de dificultad en el acceso, ponerse en contacto con cualquiera de autores del artículo a través de la dirección de correo electrónico indicada.
} 
Danza y Dramatización

http://dramatizacionydanza.blogspot.com

El principal problema al que quería hacer frente era la falta de conocimiento por parte de los estudiantes del mundo de la danza y, más concretamente, de sus distintas manifestaciones en el campo de la danza contemporánea. El blog ofrecía la posibilidad de visualizar trabajos y tomar contacto con coreógrafos muy variados y de muy distintos estilos. El blog se puso en marcha a mitad de la asignatura por uno de los profesores. Hubo dos usos principales:

- El primero fue la selección de vídeos de distintos estilos de danza contemporánea por parte del profesor. Posteriormente, los estudiantes por grupos debían elegir uno de dichos vídeos y elaborar una presentación relacionada con la coreografía, el coreógrafo o el estilo que representaba.

- El segundo uso principal fue el de dar información sobre las coreografías que cada grupo debía realizar. La información era escrita o gráfica (fotos). En los comentarios, el resto de grupos de clase debía evaluar las coreografías del resto.

Las entradas consisten en vídeos e información escrita, fotografías y comentarios escritos sobre coreografías elaboradas por estudiantes.

\section{Expresión Corporal}

http://expresioncorporalog10.blogspot.com

Se utilizó en dos tareas:

- Exposición de 4 fotogramas de forma sucesiva. Para cada fotograma, se dejó abierta durante 72 horas la posibilidad de hacer comentarios.

- En el blog se puso la información sobre el proceso que se iba a seguir en una tarea que se iba a desarrollar durante tres semanas. Cada día que se desarrollaban contenidos en clase aparecía la información en el blog. La posibilidad de hacer comentarios permanecía activa durante el tiempo que duró la tarea. Como estrategia para asegurarse el carácter secuencial de las intervenciones (y que no lo hicieran de una sola vez), con cada entrada del profesor se cerraba la posibilidad de hacer comentarios de la entrada anterior.

En ambos casos el valor de la intervención estaba expuesto en el programa de la asignatura y la intervención o no podía ser decidido por los alumnos.

- Las entradas del profesor son imágenes intencionalmente simbólicas creadas por los alumnos de cursos anteriores.

- Las entradas contenían la información sobre el proceso con enlaces a los repositorios que contenían los documentos que apoyan el proceso que se sigue. También se hicieron entradas con las incidencias del proceso.

\section{Deporte y Recreación}

http://esportirecreacio2010.blogspot.com

El blog se utilizó principalmente para continuar el debate y las reflexiones que se desarrollaban en las clases prácticas. En el blog se facilitaban los materiales escritos y audiovisuales que se utilizaban en las clases prácticas. Para asegurar que el trabajo de los estudiantes fuese continuado, la posibilidad de realizar comentarios a los post estaba activa durante dos semanas. Terminado este plazo, se desactivaba esta opción y los estudiantes no podían introducir comentarios con sus respuestas.

En este blog también se facilitaban a través de las entradas los materiales que utilizaba el profesor en sus clases teóricas y los enlaces a la bibliografía específica disponible en línea de cada uno de los temas teóricos. Además, este blog también se utilizó para informar a los estudiantes de aspectos relacionados la asignatura y para facilitarles enlaces y otro tipo de información on-line pertinente para el desarrollo de la misma. Los estudiantes también contribuyeron con la elaboración voluntaria de algún post en el blog.

Para incentivar la participación de los estudiantes en el blog, se estableció que un 20\% de la evaluación de los estudiantes en la asignatura atienda a la misma.

\section{Diseño curricular de la Educación Física}

http://dissenyef2009.blogspot.com

El blog se utilizó prioritariamente para presentar, al finalizar cada tema, las posibles preguntas de examen a las que los alumnos tenían que responder necesariamente a partir de la lectura de los apuntes y el material bibliográfico del tema facilitados por el profesor a través del Aula Virtual y también del blog. Para asegurar que el trabajo de los estudiantes fuese continuado, la posibilidad de realizar comentarios a los post con posibles preguntas de examen estaba activa durante dos semanas. Terminado este plazo, se desactivaba esta opción y los estudiantes no podían introducir comentarios con sus respuestas.

Asociado a este uso, este blog también se utilizó para informar a los estudiantes de aspectos relacionados la asignatura y para facilitarles enlaces e información on-line pertinente para el desarrollo de la misma.

Para incentivar la participación de los estudiantes en el blog, se estableció que un 20\% de la evaluación de los estudiantes en la asignatura atienda a la misma.

\section{Proyectos y materiales curriculares en Educación Física}

http://mmccef2009.blogspot.com Blogs del alumnado .(p.e: http://projecurriculum.blogspot.com, http://proyectefcafe.blogspot.com, http://materialscurriculars2009.blogspot.com)

En esta asignatura se utilizaron dos tipos de tipos de blog: el del alumno y el del profesor o asignatura.

El blog del alumno se utilizó como diario de clase donde los alumnos describían, desde un punto de vista personal, lo acontecido y los contenidos desarrollados en clase. Para ello, el alumnado tenía a su disposición todas las posibilidades que ofrece el formato blog (crear hipervínculos en los textos, añadir imágenes, audios, vídeos u otro tipo de materiales multimedia, enlazar sitios web relacionados con los contenidos de la asignatura, etc....).

El blog del profesor o de la asignatura se utilizó para dar información al alumnado sobre aspectos relacionados con el desarrollo de la asignatura.

Un 40\% de la evaluación sumativa de la asignatura se dedicó a la asistencia a las clases y su seguimiento a través del blog del estudiante. Teoría y práctica del curriculum de la Educación Física

Blogs del alumnado (p.e: http://a1-09juegosmodificados.blogspot.com, http://a1-09-inmigracion.blogspot.com)

Creación y seguimiento de un diario grupal de trabajo.

El blog se plantea como un recurso para tutorizar a los estudiantes en la elaboración de un trabajo relacionado con la parte práctica de la asignatura.

Supervisión y tutorización por parte del profesor de los trabajos desarrollados en la asignatura.

En un principio, el acceso a los blogs estaba restringido a los autores y a los profesores. Una vez finalizado el trabajo se hacía público.

Tabla 2 (continuación). Asignaturas, dirección URL del blogy descripción del uso didáctico 


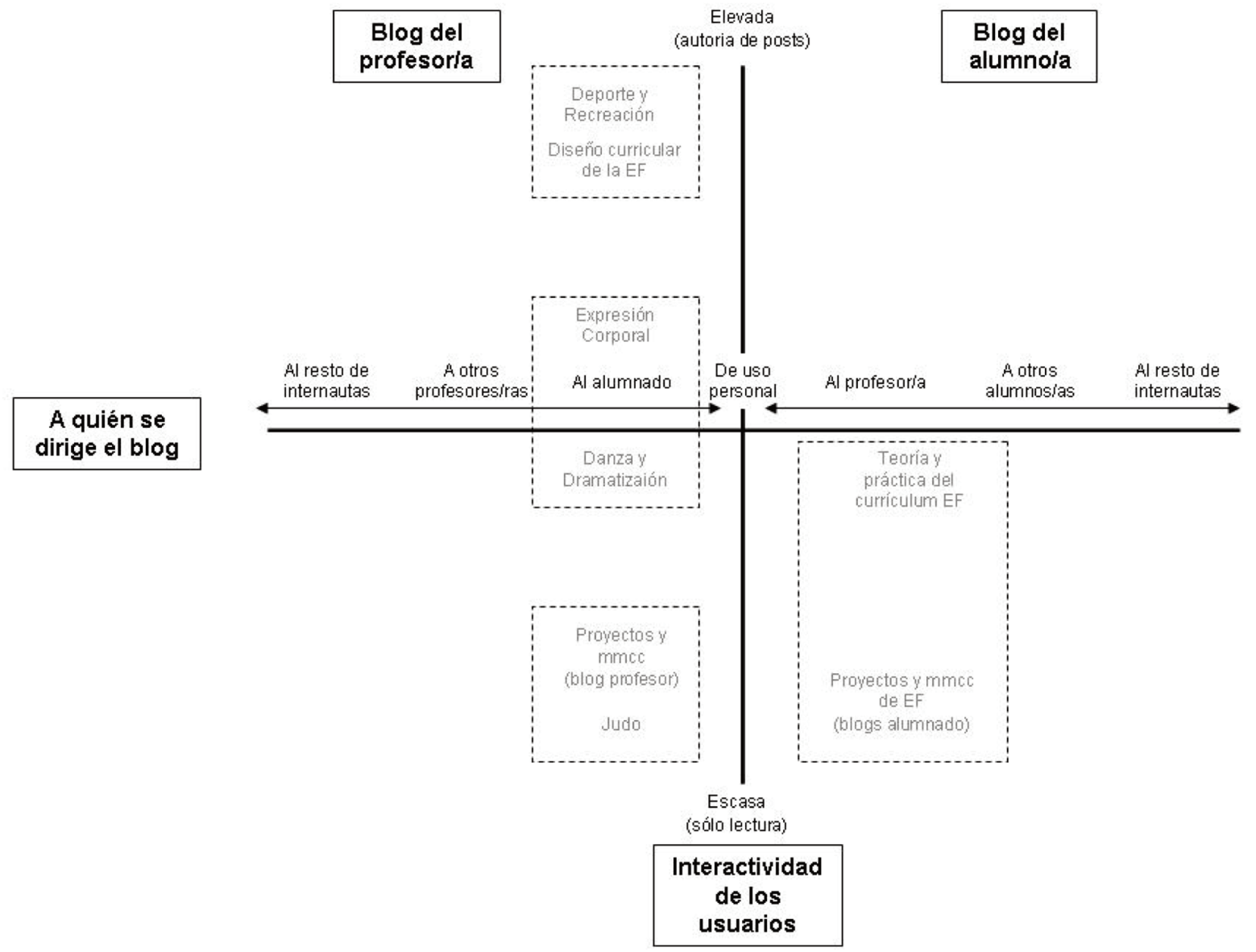

Figura 1. Matriz de usos de los blogs de la experiencia (Adaptado de Leslie, 2003)

Para caracterizar el uso de los blogs en nuestra experiencia recurrimos a la matriz propuesta por Leslie (2003) donde se sitúan usos de los blogs en la enseñanza en función de tres variables básicas:

- quién es el responsable de la administración o edición del blog (si es el profesor/a o si es el alumno/a);

- a quién se dirige el blog (si a uno mismo, al profesor o al alumno, a otros estudiantes o a otros profesores, $\mathrm{o}$ al resto de Internautas); y

- de los privilegios de participación de sus usuarios (si es un blog de lectura, aunque tenga activada la realización de comentarios, o si permite la participación de otros usuarios a través de la escritura de posts).

Sin embargo, esta última variable no recoge todas las posibilidades de interacción entre el administrador (o administradores) y el resto de usuarios, por lo que la hemos adaptado atendiendo a un continuo donde:

- el valor mínimo estaría representado por la lectura del blog, sin opción ni siquiera a efectuar comentarios a los posts,

- los valores intermedios consistirían en el grado de participación a través de la opción de los comentarios, y - el valor máximo consitiría en la posibilidad de participar en el blog a través de la publicación de posts.
Teniendo en cuenta esta modificación, la matriz resultante es la que puede verse en la figura 1, donde ubicamos el uso concreto de los diferentes blogs.

En esta matriz, además, se ha agrupado el uso de los diversos blogs de nuestra experiencia en cuatro estilos básicos que se definen y caracterizan de la siguiente forma:

a) El blog docente como transmisor de información de la asignatura. Este uso está representado por los blogs de Judo y el blog del profesor de Proyectos y materiales curriculares de la EF. Y se caracteriza por la utilización por parte del profesor del blog como un espacio virtual donde poder aportar a los estudiantes información relacionada con los contenidos o el desarrollo de la asignatura.

b) El blog docente abierto a la participación del alumnado a través de sus comentarios. Las asignaturas que hacen este tipo de uso son Expresión Corporal y Danza y Dramatización. Están caracterizados por la demanda de participación del alumnado a través de sus comentarios para la realización de actividades. Los estudiantes comentan los post que elabora el profesor.

c) El blog docente abierto a la participación del alumnado a través de sus entradas. Este modo fue el empleado en las asignaturas de Diseño curricular en EF y Deporte y Recreación. Sus características son que, además de poder realizar comentarios a los post elaborados por el profesor, los estudiantes también pueden elaborar y publicar sus post. Los estudiantes colaboran como autores del blog. 
d) Los alumnos como administradores de sus blogs, es el procedimiento que se utilizó en los blogs del alumnado de Proyectos y materiales curriculares de la EF y de Teoría y práctica del curriculum de la EF. En este uso los estudiantes se convierten en administradores de sus blogs, tomando decisiones sobre el contenido y la forma de los post, el diseño y configuración del blog, etc.

\section{Reflexiones de la experiencia educativa}

Después de la experiencia queremos subrayar algunas ideas generales que consideramos clave a la hora de plantear el uso docente de los blogs.

1. El uso de blogs permite ampliar los límites espaciotemporales del aula presencial. El uso de los blogs va más allá del aula física y del horario de clase resultando herramientas adecuadas para el desarrollo del trabajo no presencial contemplado en los nuevos créditos ECTS, así como para fomentar el aprendizaje autónomo de los estudiantes.

2. El uso de blogs no implica, per se, una mejora de los procesos de enseñanza-aprendizaje. De cuerdo con Fullan (1992), sabemos que la innovación educativa implica cambio. $\mathrm{Y}$ aunque, no siempre, un cambio implica mejora, toda mejora implica un cambio. Cuando incorporamos los blogs, $u$ otras TIC, a nuestra docencia estamos provocando un cambio, pero debemos plantearnos en qué medida este cambio contribuirá, realmente, en la mejora de nuestra docencia y en el aprendizaje de nuestros estudiantes. En nuestra opinión, la mera adopción de blogs, o de cualquier otra TIC, no garantiza la mejora de los procesos de enseñanza-aprendizaje.

3. El uso de blogs es un medio, no una finalidad. Cuando diseñamos esta experiencia no nos planteamos la utilización de los blogs como finalidad, sino como una herramienta para la mejora de los procesos de enseñanza-aprendizaje. En nuestra experiencia pretendíamos mejorar nuestra docencia o determinados aspectos problemáticos de nuestra docencia y, para ello, vimos una buena herramienta en los blogs. Consideramos que los blogs, como cualquier otra TIC, puede ser un elemento de mejora, pero, como hemos dicho, no por el mero hecho de su incorporación a la enseñanza universitaria, sino en cuanto se integren, tal y como indica Fullan (2001), dentro de nuevas destrezas docentes, nuevos comportamientos y prácticas, y nuevas creencias y concepciones educativas. Es en estos aspectos donde encontramos los auténticos elementos de innovación educativa. Los blogs pueden facilitar procesos de mejora educativa, pero también pueden terminar reproduciendo estilos de enseñanza tradicionales. En este sentido, estamos de acuerdo con Salinas (2004) en que los cambios de la Educacion Superior relacionados con las TIC suponen, principalmente, cambios en el rol del profesor, cambios en el rol del alumnado y cambios metodológicos.

4. No hay usos mejores y peores de los blogs, sino más o menos adecuados. Las características del profesorado y el alumnado, el contexto, así como los problemas y necesidades planteadas son a las que debe atender el uso de los blogs y las que marcan su adecuación didáctica. Lo que puede ser bueno para un profesor o un grupo de estudiantes puede no serlo o, incluso resultar contraproducente, para otro, y viceversa. Por este motivo, consideramos muy importante que cada uno de los profesores participantes en una experiencia de innovación educativa de las características de la que hemos comentado, comience definiendo los problemas y necesidades docentes concretas y contextuales de su asignatura. Esto evita la dispersión en posibilidades técnicas que pueden ofrecer los blogs, u otras TIC, pero que pueden no ser las necesarias o consecuentes con nuestros problemas docentes. De alguna manera debemos preguntarnos primero ¿qué problema didáctico queremos solucionar y qué necesidades didácticas queremos atender con el uso de los blogs? y después ¿de qué manera se va a usar el blog en la asignatura para solucionar este problema y atender las necesidades didácticas?

5. El uso de blogs está relacionado con la promoción de la lectura y escritura, así como a la adquisición de habilidades de comunicación. En distintos momentos de nuestra experiencia hemos sido conscientes del esfuerzo que suponía para los alumnos hacerse entender cuando se dirigen a un colectivo y trasciende la relación con el profesor en la que casi siempre predomina el carácter evaluativo. La precisión en la expresión escrita y en el uso de los conceptos es un esfuerzo que redunda en la calidad del aprendizaje. Por otra parte, no ha sido sólo un esfuerzo por el uso correcto del lenguaje escrito, la cultura multimedia de las nuevas generaciones también es una herramienta que debe ser tratada para desarrollar y plasmar el conocimiento. El uso de imágenes alusivas al conocimiento que se quiere expresar y la edición de vídeos que muestren el conocimiento adquirido exige un esfuerzo de aplicación del conocimiento de carácter simbólico que trasciende la mera reproducción de los textos.

6. La importancia del trabajo en equipo del profesorado universitario desarrollando proyectos interdiciplinares y transversales. Las conclusiones que aquí planteamos son el fruto de la discusión y evaluación de nuestra propia experiencia y las de los demás. Pero las ventajas de trabajar en equipo no se quedan en el enriquecimiento que nosotros podamos obtener, el alumnado es consciente de que por medio de una experiencia común se da consistencia y coherencia al aprendizaje. A ello puede contribuir el planteamiento de la enseñanza por competencias si las concebimos como una combinación integrada de conocimientos habilidades y actitudes conducentes a un desempeño adecuado y oportuno en diversos contextos.

Para el curso 2010-11 continuaremos nuestra experiencia de innovación a través de un nuevo proyecto que se centrará, esta vez, en la búsqueda de sistemas de evaluación continua del aprendizaje del alumnado adecuadas a las diversas formas de uso de edublogs que se han descrito en este articulo. También incorporaremos procesos de evaluación de la experiencia, a partir de las opiniones de los docentes y del alumnado.

\section{Referencias bibliográficas}

Aguaded, José I.; López Meneses, Eloy; Alonso Díaz, Laura (2010). Formación del profesorado y software social. Estudios sobre Educación, 18, pp. 97-114. http://www.unav.es/educacion/ese/pagina_8.html Fecha de consulta, 10.01.2011.

Blanco, Sonia (2005). Los weblogs como herramienta didáctica en el seno de una asignatura curricular. En G. García (Coord.). El ecosistema digital: modelos de comunicación, nuevos medios y público en Internet, Valencia: Servei de Publicacions de la Universitat de València, pp.151-166.

http://www.uv.es/demopode/libro1/SoniaBlanco.pdf Fecha de consulta, 08.05.2010.

Comisión para la Renovación de las Metodologías Educativas en la Universidad (2006). Propuesta para la renovación de las metodologías educativas en la 
Universidad. Madrid: Secretaria General Técnica. Subdirección General de Información y Publicaciones del MEC.

http://www.educacion.es/dctm/mepsyd/educacion/u niversidades/estadisticas-informes/estadisticas/propuestarenovacion.pdf?documentId=0901e72b80048b7 o Fecha de consulta, 08.05.2010.

Farmer, Brett; Yue, Audrey; Brooks, Claire (2008). Using blogging for higher order learning in large cohort university teaching: A case study. Australasian Journal of Educational Technology, 24(2), pp. 123-136. http://www.ascilite.org.au/ajet/ajet24/farmer.html Fecha de consulta, 10.01.2011.

Fraile, Antonio (2002). El seminario colaborativo: una propuesta formativa para el profesorado de Educación Física. Contextos educativos: Revista de educación, 5 , pp. 101-122. http://dialnet.unirioja.es/servlet/articulo? codigo $=498275$ Fecha de consulta, 11.01.2011.

Fullan, Michael G. (1992). Successful School Improvement: the implementation perspective and beyond. Buckingham: Open University Press.

Fullan, Michael G. (2001). The new meaning of educational change ( $3^{\mathrm{a}}$ ed.). Nueva York: Teacher College Press, University of Columbia.

Gewerc, Adriana (2005). El uso de weblogs en la docencia universitaria. Revista Latinoamericana de Tecnología Educativa. 4, 1, 9-23.

http://campusvirtual.unex.es/cala/editio/index.php?j ournal $=$ relatec $\&$ page $=$ article $\&$ op $=$ view $\&$ path []$=173 \& p$ ath[]=163 Fecha de consulta, 03.05.2010

González Sánchez, Rocío y García Muiña, Fernando E. (2009). El blog en la docencia universitaria cuna herramienta útil para la convergencia europea? Relada, 3(2), pp. 135-144.

http://serviciosgate.upm.es/ojs/index.php/relada/arti cle/viewFile/70/70 Fecha de consulta, 03.05.2010.

Ladyshewsky, Richard K.; Gardner, Peter (2008). Peer assisted learning and blogging: A strategy to promote reflective practice during clinical fieldwork. Australasian Journal of Educational Technology, 24(3), 241-257. http://www.ascilite.org.au/ajet/ajet24/ladyshewsky.ht $\mathrm{ml}$ Fecha de consulta, 10.01.2011.

Leslie, Scott (2003). Matrix of some uses of blogs in education. http://www.edtechpost.ca/wordpress/2003/10/09/matrix-of-some-uses-of-blogs-in-educat ion/ Fecha de consulta, 08.05.2010

López Meneses, Eloy; Martín Sánchez, Miguel Ángel

(2009). Experiencias universitarias de innovación para la mejora de la práctica educativa en el contexto europeo. @tic. Revista d'innovació educativa, 2 [Docentic] http://ojs.uv.es/index.php/attic/article/view/8o/119 Fecha de consulta, 03.05.2010.
Marzal, Miguel Ángel; Butera, María Jesús (2007). Los blogs en el nuevo modelo educativo universitario: posibilidades e iniciativas. BID: textos universitarios de biblioteconomía y documentación,19.

http://www.ub.es/bid/19marza2.htm Fecha de consulta, 03.05.2010.

Ministerio de Educación, Cultura y Deporte (2003). Integración del sistema universitario español en el Espacio Europeo de Educación Superior.

Documento-marco. http://www.eees.es/pdf/Documento-Marco_10_Febrero.pdf Fecha de consulta, 08.05.2010.

Orihuela, José Luis; Santos, María Luisa (2004). Los weblogs como herramienta educativa: Experiencias con bitácoras de alumnos. Quaderns Digitals, 35, pp. 1-7. http://www.quadernsdigitals.net/index.php?accionMenu=hemeroteca.DescargaArticuloIU.descarga\&tipo= PDF\&articulo_id=7751 Fecha de consulta, 03.05.2010.

Philip, Robyn; Nicholls, Jennifer (2009). Group blogs: Documenting collaborative drama processes. Australasian Journal of Educational Technology, 25(5), pp. 683-699.

http://www.ascilite.org.au/ajet/ajet25/philip.html Fecha de consulta, 10.01.2011.

Salinas, Jesús (2004). Innovación docente y uso de las TIC en la enseñanza universitaria. Revista Universidad y Sociedad del Conocimiento, 1 (1). http://rusc.uoc.edu/ojs/index.php/rusc/article/view/ 228 Fecha de consulta, 07.06.2010.

Servei de Formació Permanent (2005). Ensenyament $i$ Convergència Europea. Apunts per al debat i la reforma. València: Servei de Formació Permanent de la Universitat de València.

Williams, Jeremy B.; Jacobs, Joanne (2004). Exploring the use of blogs as learning spaces in the higher education sector. Australasian Journal of Educational Technology, 20(2), pp. 232-247. http://www.ascilite.org.au/ajet/ajet20/williams.html Fecha de consulta, 10.01.2011. 